\title{
Modeling and Simulation of Three Phase Induction Machine Using Written Pole Technology
}

\author{
Kishor S. Deshmukh ${ }^{1}$, Dr. Prof. Kamal Bansal ${ }^{2}$, Dr. Atul Killedar ${ }^{3}$ \\ ${ }^{I}$ PhD Scholar, Electrical and Electronics Engg., University of Petroleum and Energy Studies, Dehradun \\ ${ }^{2}$ Dean and Professor, College of Engineering, University of Petroleum and Energy Studies, Dehradun \\ ${ }^{3}$ Manager, Chemical Technology, Vishay Components India Pvt. Limited, Pune
}

\begin{abstract}
Three phase induction motors are employed in almost all the industries because of its simple construction and easy operation. Efficiency of the induction motor is affected by its fixed losses and variable losses which mainly depend on the input supply voltage and load current respectively. An attempt is made to minimize the iron losses by using the permanent magnet ferrite. A new Three Phase Induction Motor Using Written Pole Technology is proposed in this paper in which stator consists of two three phase windings accommodated in the same stator core and rotor is used as squirrel cage rotor with ferrite material on its periphery. Shaft loads are categorized as low, medium and high, Stator coils are energized through a controller based on the load demand. In this study, it is suggested to operate the machine with flat efficiency characteristics, irrespective of shaft load. When compared to conventional induction motor, the motor efficiency and power factor are improved. Another approach of this machine is that the ferrite layer on the rotor periphery will reduce the motor losses which results in improving the motor efficiency. In this motor, one windings (main winding) is designed for the 238 volt ac voltage while the second winding (exciter winding) is designed for 8 volt high frequency ac voltage. Experimental result ensures the considerable increase in the efficiency and power factor.The aim of this paper is to analyze and simulate performance of a $1 \mathrm{Hp}$ three phase induction motor using written pole technology using the well known Park's transformation. A three phase squirrel cage machine is reconfigured and modeled into a two three phase stator winding accommodate in same stator core of the same volume as the three phase machine. Different tests are carried out on the novel machine to determine machine parameters. Simulation results, that predicts the dynamic performance of the machine using ANSYS, at start up are presented and discussed.
\end{abstract}

Keywords: Three phase induction motor with written pole technology, dq-Transformation, Simulation, Transient Analysis, Reliability.

\section{Introduction}

The induction machine is considered the workhorse of the industry, $65 \%$ of the total energy demand industrially is from induction motors. Induction machines has almost replaced the DC machines in the industry due to the simplicity of design, ruggedness, low cost, low maintenance cost and direct connection to AC power source compared to the DC motors. The application of induction machines in industrial, commercial and domestic sectors are numerous and as such research work becomes endless. Due to the importance of induction motors, new strategies and configurations of design are being sought that are capable of improving efficiency. Induction motors are employed in Textile mills, Agriculture and almost all the manufacturing industries to drive the loads because of its rugged in construction and ease of operation. The major limitation of induction motor is its efficiency and power factor. These two parameters depend on the shaft load. In conventional induction motor, only mechanical output is available and hence, its power factor and efficiency is limited. Written pole induction motor with dual stator winding would be the better choice to overcome these limitations. Written-Pole Motors offer a revolutionary method for powering large horsepower applications in locations where only singlephase power is available. The Written-Pole motor is a hybrid concept, which utilizes basic concepts from induction, hysteresis and permanent magnet motors, with several important distinctions. The primary feature which differentiates Written-Pole motors from more conventional designs is a continuous layer of ferrite magnets on the surface of the rotor, along with a high-density exciter winding contained within the stator winding. This unique design matches the pole structure of the rotor to the rotational speed of the motor.

The result is a motor that combines the desirable starting characteristics of a high-slip, high-power factor cage motor with the energy-efficient operation of an AC permanent magnet motor-- without relying on power electronics, reduced voltage starters or phase converters [1].

Dual stator induction motor became popular since 1930. When a three phase supply is applied to one of the stator windings, a revolving magnetic field of constant magnitude is developed in the air gap and this field is shared by both the windings [2]. 
The various possibilities in the design modification, speed control, efficiency, power factor improvement of induction motor and double winding induction motors are discussed below. Dual stator induction motor stator with two separate windings wound for a dissimilar number of poles is fed from an independent variable-frequency variable-voltage inverter. This drive offers advantages as speed sensor less operation, Zero speed operation is achieved by independently controlling the two sets of stator current and hence, maintaining a minimum electrical frequency independent of mechanical speed. This drive is suited for either constant volts per hertz or filed oriented operation. Circulating harmonics currents are eliminated by the dissimilar number of poles [3]. Three-phase induction motors are designed to meet high starting torque, good operating efficiency and power factor. Optimization design of three-phase induction motor is formulated as a nonlinear multivariable programming problem to meet the above requirements. The simulated annealing algorithm was used to obtain an optimum design [4]. Any significant improvement in the operating efficiency of induction motor will be effort at energy conservation. The optimized design of induction motor can be obtained using Rosenbrock's method to minimize the cost of active materials, the annual energy consumed and the total annual cost [5].

The stator of a double winding induction motor can be connected in star and delta, thereby active resistance by $11 \%$ and inductance by $13 \%$ can be reduced. The active resistance decreases to considerable value and hence copper losses are decreased. DWIM has increase of output power and torque of $10 \%$ and starting torque reduced by $3.5 \%$ [6]. A $3.7 \mathrm{~kW}$ three phase induction motors are widely used in agriculture and industries. During rewinding process, efficiency get reduced by five percentage points due to improper rewinding process in which the winding conductor size is reduced by 1 SWG or by reducing number of turns from the winding specification. This improper rewinding practice results in reduction of torque per ampere and increase in winding temperature for the given load. [7]. Efficiency of the induction motor can be optimized even at lightly loaded condition by means of TRIAC fed drive. Input voltage is adjusted based on the optimalefficiency and power factor. More than $10 \%$ efficiency improvement is possible even at one fourth of the full load [8]. Dual stator induction motor suggested for energy conservation consists of two sets of RUN windings. The main RUN winding is energized to have sufficient MMF in order to produce sufficient magnetic flux and to operate the motor at light loads with good power factor. In this machine reduced power is applied to the second set of RUN winding and hence, the power consumed due to eddy currents, copper losses and poor power factor are considerably reduced [12]. The efficiency of an induction motors ranges between 0.75 and $22 \mathrm{~kW}$ can be improved by means of die cast copper instead of aluminium cage rotor with premium steel core [13]. In multi flux level of a three-phase squirrel-cage induction motor, the efficiency and power factor can be both maximized as a function of load. The stator winding with two sets of turns, shares the same positions in the stator slots. Among all the possible stator winding connections, six modes were selected and analyzed [16]. Efficiency of an induction motor can be improved by cutting the predefined arc-section of the rotor. Air gap over a periphery will not be uniform and causes edge effect. The redesign is focused on construction of the rotor with novel windings configurations [17]. Optimal values of induction motor design parameters can be determined using Particle Swarm based approach to three-phase Induction Motor based on particle-swarm-optimization (PSO) technique. This method shows improvement in efficiency, active material cost, and performance under starting and full load conditions [18]. Dual stator induction motor can be operated in power balancing mode and maximum efficiency mode for effective utilization of the machine. Second set of stator winding can feed electrical loads, thereby power factor and efficiency is improved [19]. Written pole machines are perceived to offer many advantages such as improved magneto motive force (MMF) waveforms, reduced line voltages and increased efficiencies. The consequential benefits of these are reduced torque pulsations, lower losses, reduced acoustic noise and reduced power ratings of supply converters [1]. The modeling of three phase induction machine with written pole technology is carried out here. The three phase induction motor with written pole technology consists of two three phase stator winding accommodate on same stator core and rotor with permanent magnet ferrite layer on its periphery. The $\mathrm{d}-\mathrm{q}$ voltage equations in the arbitrary reference frame of a three phase induction machine with written pole technology are readily written as in [4 \&5]:

Voltage equation for main stator winding:

$\mathrm{V}_{\mathrm{ABC}}=\mathrm{Rs}_{1} \mathrm{I}_{\mathrm{ABC}}+\frac{d}{d t} \lambda_{\mathrm{ABC}}$

Voltage equation for exciter winding:

$\mathrm{V}_{\mathrm{XYZ}}=\mathrm{Rs}_{2} \mathrm{I}_{\mathrm{XYZ}}+\frac{d}{d t} \lambda_{\mathrm{XYZ}}$

Voltage equation for rotor winding:

$\mathrm{V}_{\mathrm{abc}}=\mathrm{R}_{\mathrm{r}} \mathrm{I}_{\mathrm{abc}}+\frac{d}{d t} \lambda_{\mathrm{abc}}$ 


\section{Three Phase Induction Machine With Written Pole Technology Modelling}

To model a three phase induction machine with written pole technology, precise corporation, Florida patented written pole induction motor which works on single phase supply and having hp rating above $10 \mathrm{hp}$ only. So, in this paper, a novel motor with two stator winding i.e. main winding and exciter winding are placed on same stator core. Main winding is placed in 36 stator slots with 4 poles and star connected for $1 \mathrm{hp}$ output and delta connected for $3 \mathrm{hp}$ output and exciter winding is wound on three different stator teeth and is star connected. In novel motor,

squirrel cage rotor with permanent magnet ferrite layer on its periphery is used.

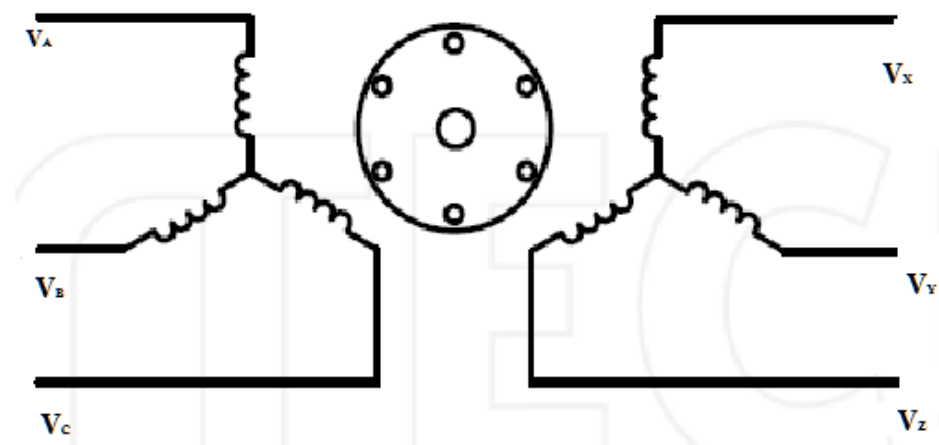

Figure 1: Winding arrangement of Main and Auxiliary Windings

\section{D - Q Modeling Of Three Phase Induction Motor with Written Pole Technology}

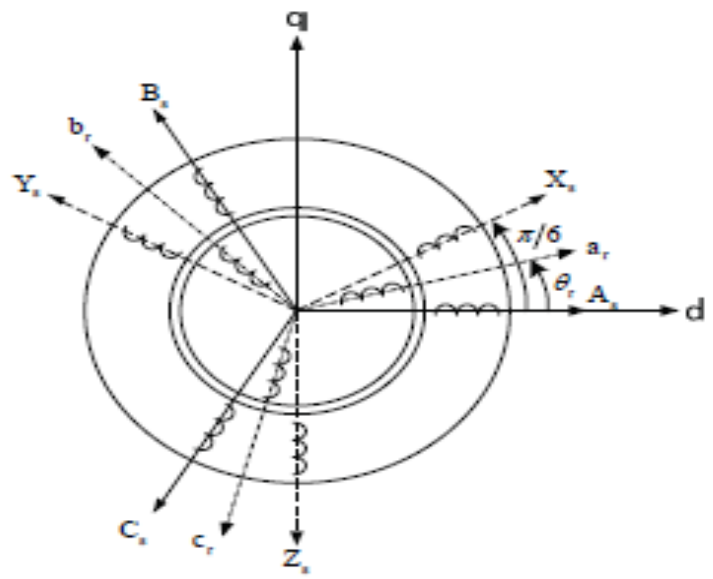

Figure 2: Stator main, exciter windings, rotor windings and phasors

For three phase induction motor with written pole technology, the concept of variable transformation is being applied as in [21]. Induction motor configurations with multiple sets of three-phase stator windings and with an arbitrary number of phases have been extensively studied in [20]. A study conducted in [20], concluded that it is advantageous to use asymmetrical stator winding structure with two three-phase winding spatially shifted by 300, as against a symmetrical winding structure with a 600 spatial shift between any two consecutive phases. In order to model the three phase induction motor with written pole technology, the $\mathrm{d}-\mathrm{q}$ transformation and the well known reference frame theory is adopted for modeling based on the operating condition of the sample machine. In this research work, different reference frames are developed and the rotor reference frame is used for analysis.

\section{Rotor Reference Frame Model}

The three phase induction motor with written pole technology with two stator winding sets in one stator core. The voltage equations can be transformed in to arbitrary reference frame as

$V_{q 0 a b c}=R_{r} I_{q a b c}+\left(\omega-\omega_{r}\right) \lambda_{d a b c}+p \lambda_{q a b c}$

$V_{d 0 a b c}=R_{r} I_{d a b c}-\left(\omega-\omega_{r}\right) \lambda_{q a b c}+p \lambda_{d a b c}$

The flux linkage equations are given below. 


$$
\begin{aligned}
& \lambda_{q A B C}=\left(L_{1 S}+L_{m}\right) I_{q A B C}+L_{m} I_{q X Y Z}+L_{m} I_{q a b c} \\
& \lambda_{d A B C}=\left(L_{1 S}+L_{m}\right) I_{d A B C}+L_{m} I_{d X Y Z}+L_{m} I_{d a b c} \\
& \lambda_{0 A B C}=\left(L_{1 S}+L_{m}\right) I_{0 A B C}+L_{m} I_{0 X Y Z}+L_{m} I_{0 a b c} \\
& \lambda_{q X Y Z}=L_{m} I_{q A B C}+\left(L_{2 S}+L_{m}\right) I_{q X Y Z}+L_{m} I_{q a b c} \\
& \lambda_{d X Y Z}=L_{m} I_{d A B C}+\left(L_{2 S}+L_{m}\right) I_{d X Y Z}+L_{m} I_{d a b c} \\
& \lambda_{0 X Y Z}=L_{m} I_{0 A B C}+\left(L_{2 S}+L_{m}\right) I_{0 X Y Z}+L_{m} I_{0 a b c} \\
& \lambda_{q a b c}=L_{m} I_{q A B C}+L_{m} I_{q X Y Z}+\left(L_{l r}+L_{m r}\right) I_{q a b c} \\
& \lambda_{d a b c}=L_{m} I_{d A B C}+L_{m} I_{d X Y Z}+\left(L_{l r}+L_{m r}\right) I_{d a b c} \\
& \lambda_{0 a b c}=L_{m} I_{0 A B C}+L_{m} I_{0 X Y Z}+\left(L_{l r}+L_{m r}\right) I_{0 a b c} \\
& \text { Where, } \\
& \mathrm{L}_{\mathrm{m}}=\frac{3}{2} \mathrm{~L}_{\mathrm{ms}} \\
& \mathrm{L}_{\mathrm{mr}}=\frac{3}{2} \mathrm{~L}_{\mathrm{mr}}
\end{aligned}
$$

Where, the subscripts ' 1 ' refers to main winding and ' 2 ' refers to exciter winding and ' $r$ ' refers to rotor winding. And $\omega$ is the rotational speed of reference frame and $\omega_{\mathrm{r}}$ is the rotational speed of rotor.

We use state variable method to arrange equation (1) to (5) for computer simulation. The electromagnetic Torque, $\mathrm{T}_{\mathrm{em}}$, is given as

$$
\mathrm{T}_{\mathrm{em}}=\frac{3}{2} \frac{P}{2}\left(\lambda_{d A B C} I_{q A B C}-\lambda_{q A B C} I_{d A B C}+\lambda_{d X Y Z} I_{q A B C}-\lambda_{q X Y Z} I_{d X Y Z}\right)
$$

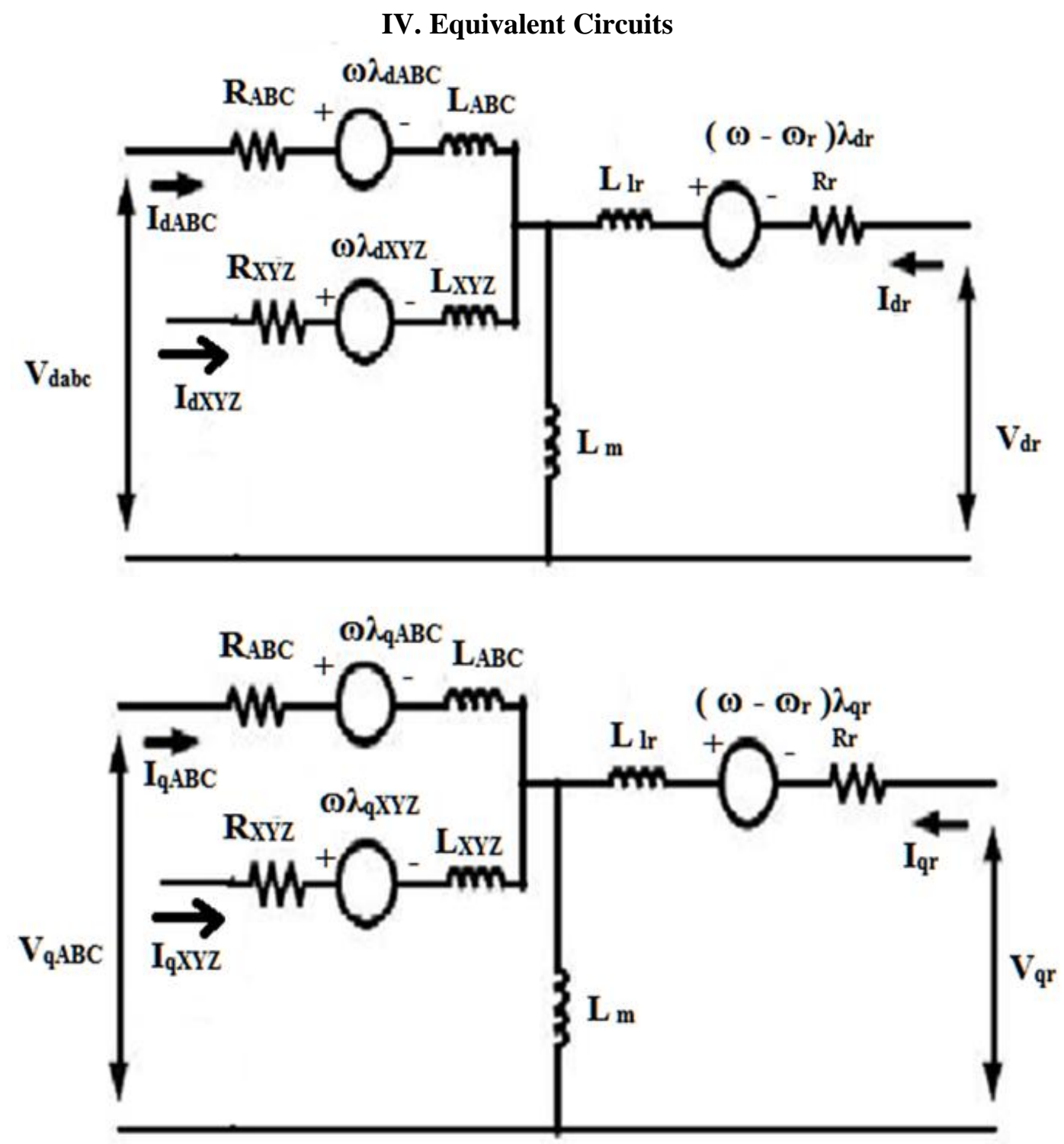

Figure 3: Equivalent ' $q d$ ' circuit diagrams 


\section{Computer Simulation}

The differential equations 1-5, where arranged using state variable analysis. ANSYS programs were developed to simulate the performance of the test machine. The result of the simulation is presented below;

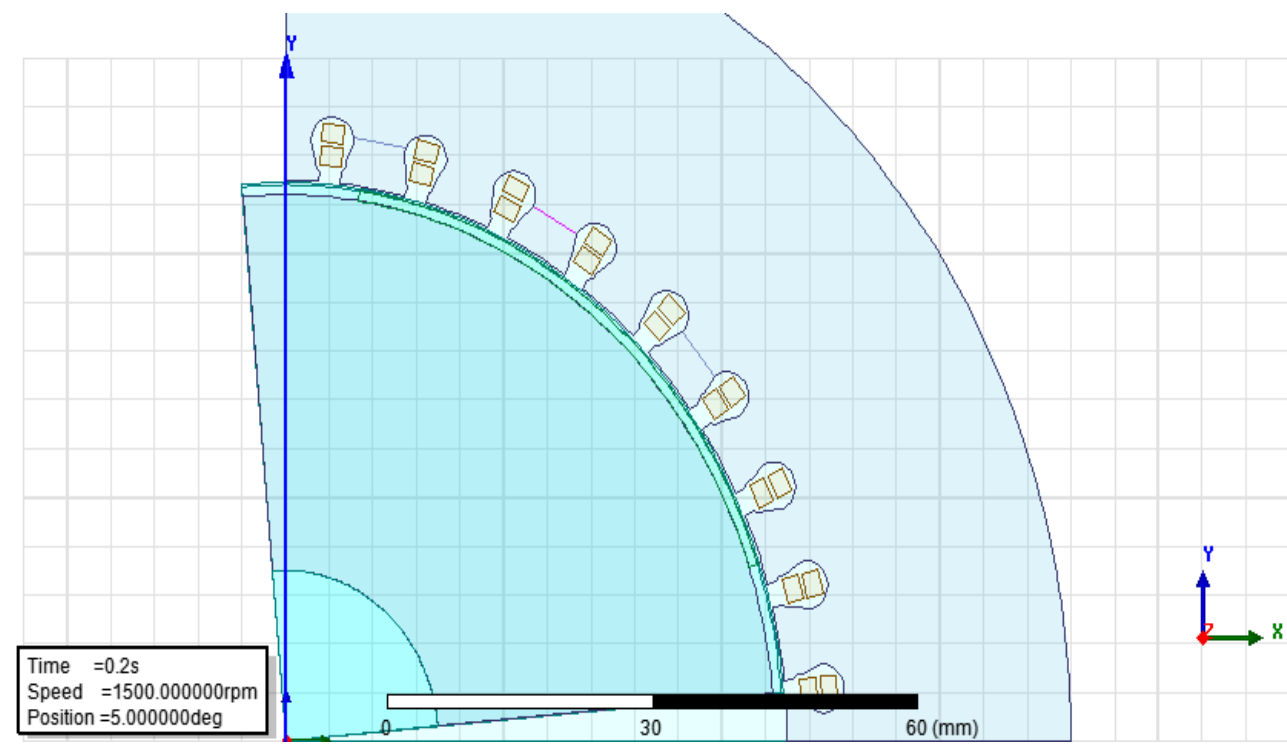

Figure 4: Modeling in Maxwell Ansys 16.0

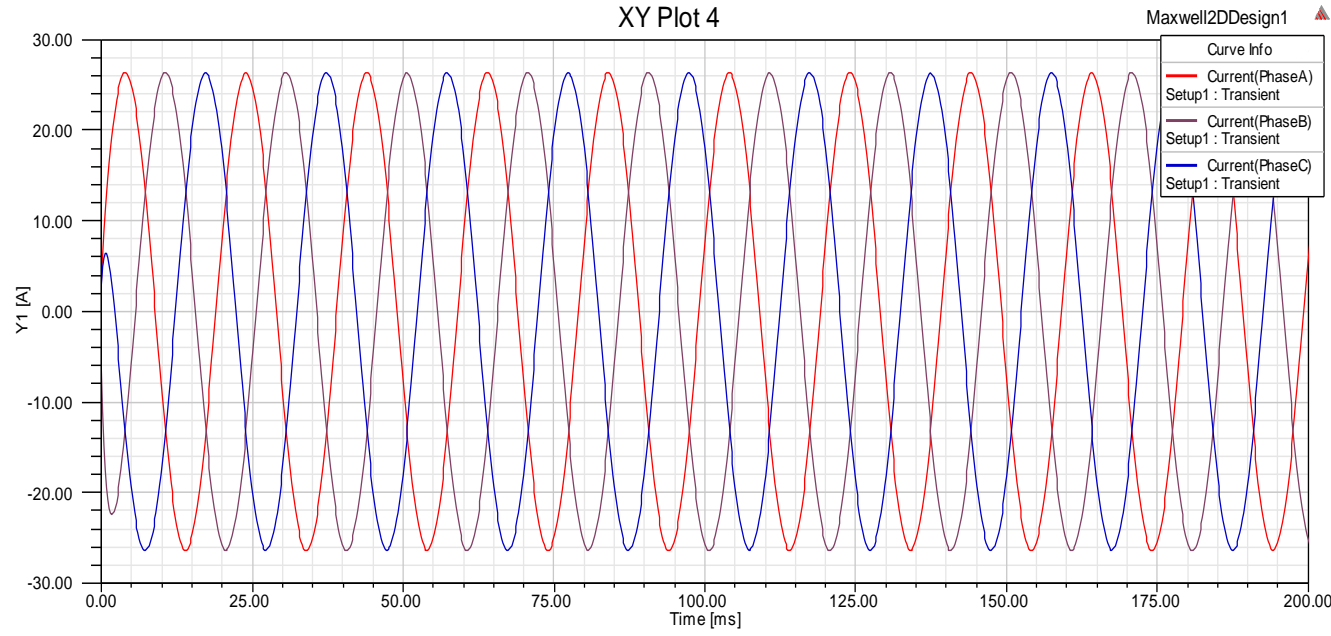

Figure 5.Currents in Main windings A,B \&C

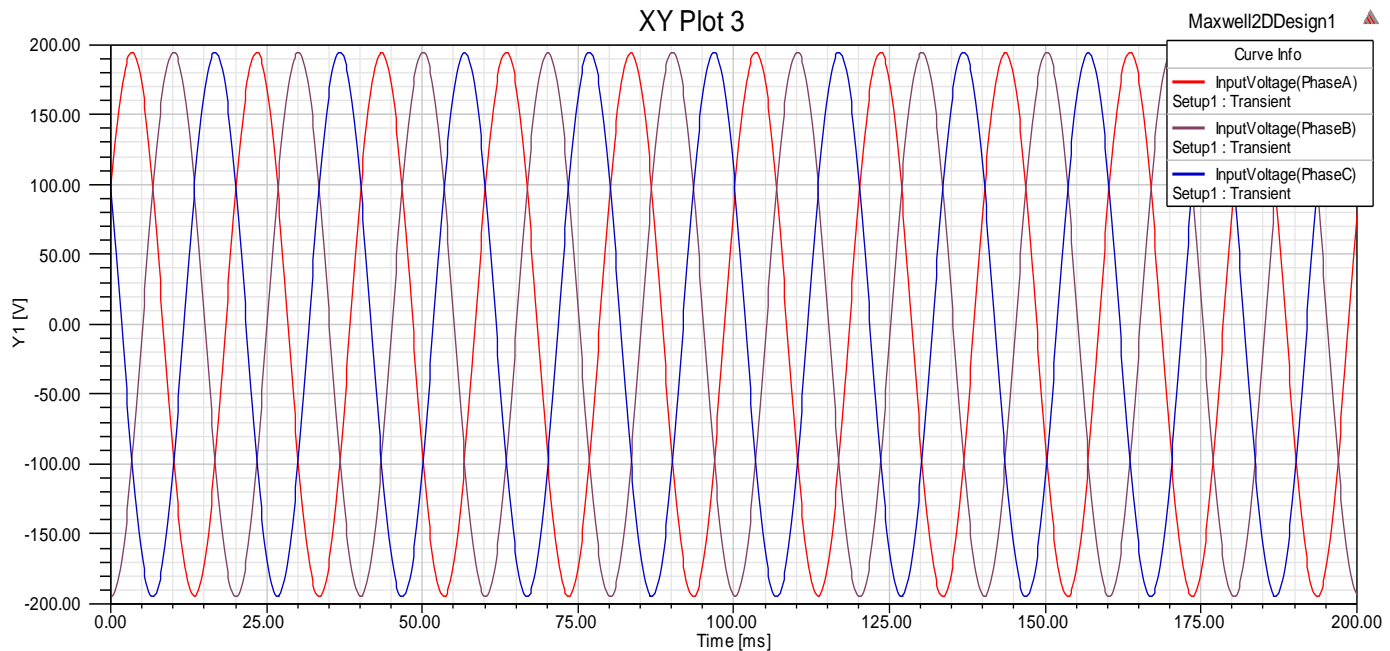

Figure 6.Input Voltages in Main windings A,B \&C 


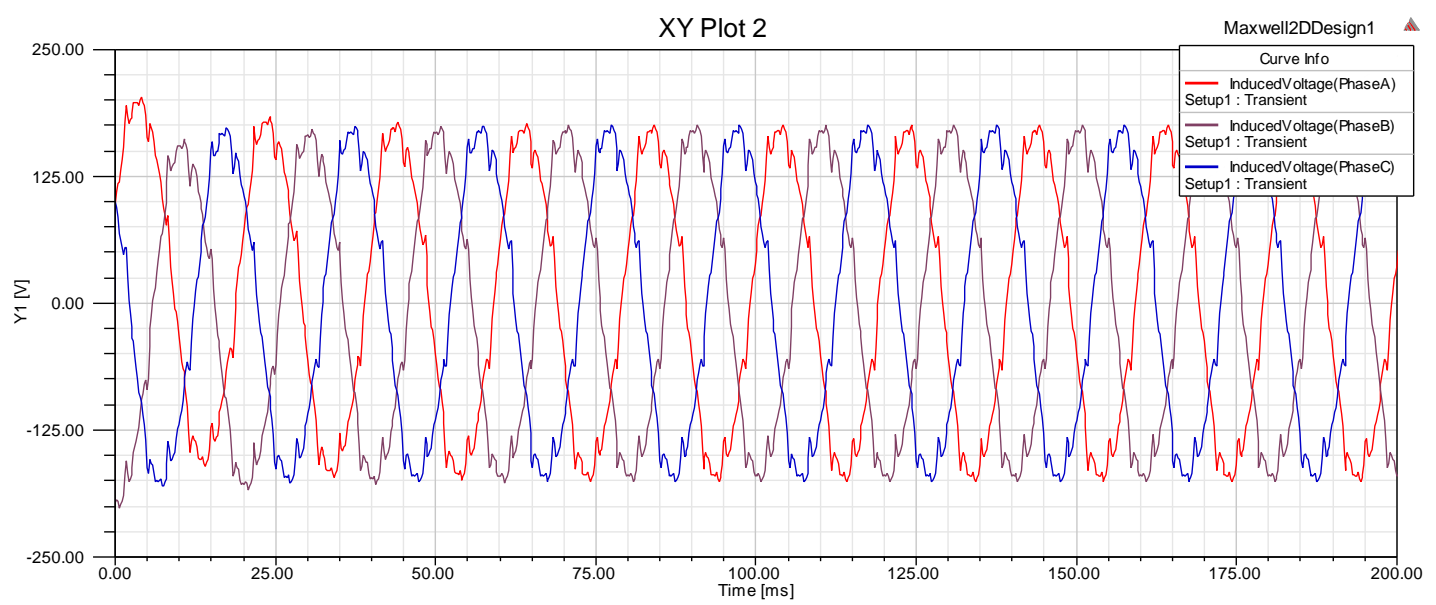

Figure 7.Induced Voltages in Main windings A,B \&C

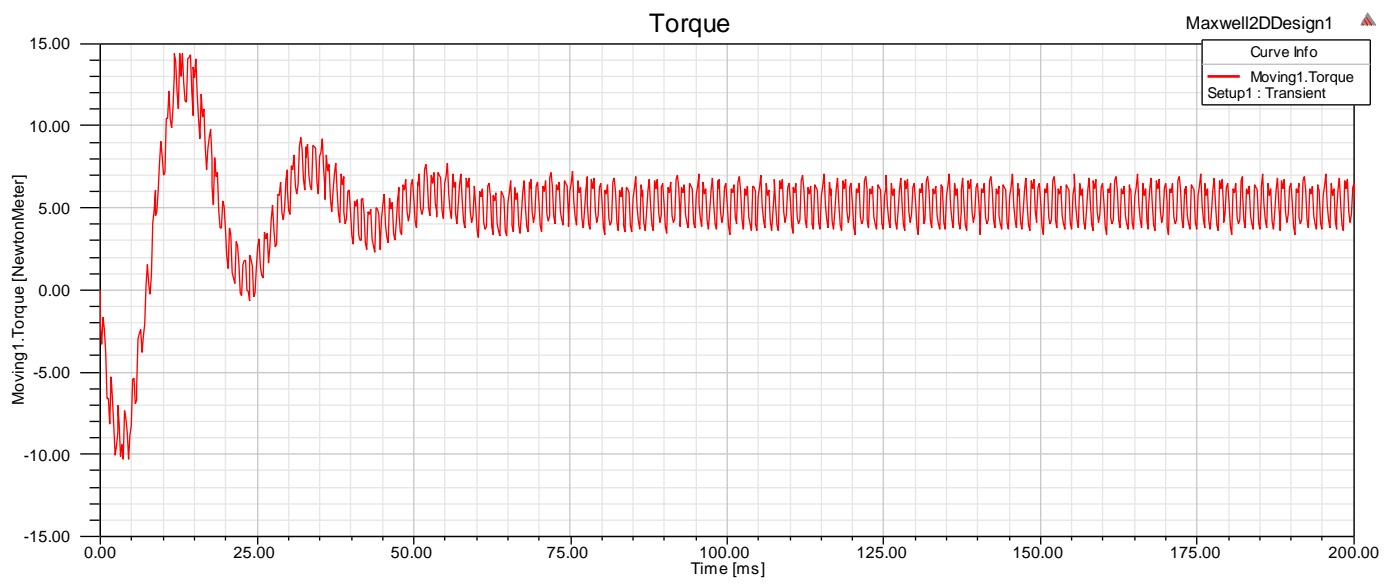

Figure 7.Moving Torque of Motor

\section{Discussion Of Results}

The test machine, three phase induction motor with written pole technology is described by a system of differential equations. The number of equations predicting the performance of the machine is equal to the number of winding sets in the stator and rotor circuits. In the first instant, the conventional model is simulated and the results shows that the phase current stabilizes at 0 seconds, the moving torque reaches synchronization at 50 mseconds.

\section{Conclusion}

The application of three phase induction motor with written pole technology is mainly in high powerhigh current applications so the use of inductor for current injection is uneconomical.Though the initial cost of three phase induction motor with written pole technology is increased as compared to conventional three phase induction motor, at the same time efficiency and torque are significantly improved, the energy savings in applying energy efficient motors will pay off the additional cost of the machine. Hence, three phase induction motor with written pole technology is a potential competitor with three phase machines mostly in areas where reliability is an issue.

\section{References}

[1]. S. Hoffman, B. Banerjee, and M. Samotyj, "Written-pole Revolution,” IEEE Power Eng. Rev., pp. 6-9, 1997.

[2]. P.L. Alger, E.H.Freiburghouse and.D.Chase, "Double windings for flexible alternators", AIEE Transactions, Vol.49, January 1930, pp. $226-244$.

[3]. Alfredo Munaz-Garcia, Thomas A.Lipo, "Dual stator winding Induction Machine Drive", IEEE Transactions on Industry Applications, Volume 36, Issue 5, Sep/Oct 2000 pp.1369 - 1379.

[4]. Bhuvaneswari, R., Subramanian, S. (2005), "Optimization of three phase induction motor design using simulated annealing algorithm", Electric Power Components and Systems, Vol. 33, pp.947-56.

[5]. Murthy, S.S., Singh, B.P." Power Electronics, Drives and Energy Systems for Industrial Growth", Proceedings of the 1996 International Conference on Volume 1, Issue, 8-11 Jan 1996, pp.458 - 462 vol.1.

[6]. Luan Ahma, Nysret Avdiu, “An analysis of Induction motor with Two stator windings connected in Star and Delta connection supply from three phase network." IEEE, PEDES-2006, International Conference on Power Electronics, Drives and Energy Systems 
for Industrial growth-2006.

[7]. V. Prakasha, S. Baskar, S. Sivakumar and K. Sri Krishna "A novel efficiency improvement measure in three-phase induction motors, its conservation potential and economic analysis" International Energy Initiative, Inc. Published by Elsevier Inc. Vol. 12, June 2008, pp. 78-87

[8]. Benbouzid, M.E.H.; Beguenane, R.; Dessoude, M.; Hubbi, W., "Energy optimized control strategy for a variable input voltage three-phase induction motor" IEEE International conference on Electric Machines and Drives Conference Volume, Issue, 18-21 May 1997 Page(s):MD2/5.1 - MD2/5.3.

[9]. Hubert.Razik, Abderrezak Rezzoug, Djafar. Hadiouche "Modelling and Analysis of Dual - Stator Induction Motors", IEEJ Transcations Industrial Applications, Vol. 125,2005 pp. 1093-1104.

[10]. Lilibu, Chunhi, Jeffkrukowski, Wilsun Xu, Xian hiu, "A New Energy Recovery Double Winding Cage-Rotor Induction Machine" IEEE Transactions on Energy Conversion, Vol.18 June 2002, pp. 315 - 320

[11]. Grantham, C. Tabatanaei-Yazdi, H. Rahman, M.F. "A novel method for rapid efficiency measurement of three phase induction motors", IEEE Transaction on Energy Conversion, 1999, Vol. 14, pp. 1236-1240

[12]. Harold J. Weber, "A.C.Induction motor energy conserving power control method and apparatus" US Patent: 4806838, February 21, 1989.

[13]. F.Parasiiti.,M.Viiani, C. Walti., G, Songini., A. Novelto,T. Rossi "Three-Phase Induction motor Efficiency Improvements with Die -cast copper rotor cage and premium steel", SPEEEDAM 2004, June 16-18, CAPRI (Italy).

[14]. C.Thangaraj, S.P.Srivastava and Pramod Agarwal"Energy Efficient Control of Three-Phase Induction Motor - A Review" International Journal of Computer and Electrical Engineering, Vol.1, 2009, pp.61-70.

[15]. Al-Ali, AR; Negm, MM; Kassas, M “A PLC Based Power Factor Controller For A 3-Phase Induction Motor" Conference record of the 2000 IEEE Industry applications conference, pp.1065-1072.

[16]. Ferreira, F.J.T.E. de Almeida, A.T, "Novel Multiflux Level,Three- Phase, Squirrel-Cage Induction Motor for Efficiency and Power Factor Maximization" Energy Conversion, IEEE Transactions, 2008 Vol:23, pp: 101-109.

[17]. Al-Khalaf Bani-Younis, Jihad; Ferrah, Azzeddine; Tami, Abdelkader;Bouzguenda, Munir, "Design of a segment-stator induction motor with optimum efficiency", International Journal of Applied Engineering Research Article, 2008

[18]. R. Kannan, R. Bhuvaneswari, and S. Subramanian, “Optimal Design of Three-Phase Induction Motor Using Particle Swarm Optimization" Iranian Journal of Electrical and Computer Engineering, VOL. 6, 2007 pp 105-111.

[19]. Chandrasekaran.V, Manigandan. T, “An InnovativeApproach forEnergy Conservation in Induction Motor”, International Conference on Man-Machine Systems (ICoMMS), 11 - 13, October 2009. Batu Ferringhi, Penag, Malaysia,pp IB2-1 - IB2- 6.

[20]. Yuriy Kats, ‘Adjustable speed drives with multiphase motors',IEEE Transaction, 1997.

[21]. Lipo, T. A. - A d-q model for six phase induction machines, Proceedings of the Int'l Conf. on Electrical Machines, Athens, pp. $860-867$, Sept 1980 .

[22]. E. J. Akpama and O. I. Okoro, -Simulating Asynchronous Machine with Saturation effect, Proc of ESPTAEE Conf., UNN, pp130-135, June 2008 . 